\title{
Biventricular Hypertrophy by ECG Finding
}

National Cancer Institute

\section{Source}

National Cancer Institute. Biventricular Hypertrophy by ECG Finding. NCI Thesaurus. Code C106502.

An electrocardiographic finding suggestive of enlargement or thickening of both ventricles, with a combination of findings which are related to $\mathrm{LVH}$ and $\mathrm{RVH}$, such as voltage criteria for LVH in the presence of marked right axis deviation. (CDISC) 